\title{
An Integrated Approach for Fuzzy Failure Modes and Effects Analysis using Fuzzy AHP and Fuzzy MAIRCA
}

Soumava Boral ${ }^{1,2}$, Ian Howard ${ }^{2 *}$, Sanjay K. Chaturvedi ${ }^{1}$, Kristoffer McKee ${ }^{2}$, V.N.A. Naikan ${ }^{1}$,

${ }^{1}$ Subir Chowdhury School of Quality and Reliability, Indian Institute of Technology

Kharagpur, Kharagpur, India - 721302

${ }^{2}$ School of Civil and Mechanical Engineering, Curtin University, WA - 6102

[*Communicating author = I.Howard@exchange.curtin.edu.au $]$

\begin{abstract}
:
Failure mode and effect analysis (FMEA) is a proactive risk assessment technique, which has been widely used by engineers to meet the safety and reliability requirements of processes, products, structures, services and systems. The major aim of the FMEA technique is to rank the failure modes according to their risk levels and subsequent actions are performed to eliminate/mitigate their consequences. In a typical FMEA, for each failure mode, three risk factors, namely severity (S), occurrence $(\mathrm{O})$ and detection (D) are evaluated and a risk priority number (RPN) is estimated by multiplying these risk factors. In recent years a significant effort has been underway and different approaches have been proposed to improve FMEA, to overcome its several drawbacks. We notice that there is a significant amount of literature based on multicriteria decision making (MCDM) methods, which have been solely aimed to improve the risk estimation process in FMEA by overcoming the drawbacks of the traditional FMEA technique. In this work, we propose a novel integrated MCDM approach by combining Fuzzy Analytical Hierarchy Process (FAHP) with the modified Fuzzy Multi-Attribute Ideal Real Comparative Analysis (modified FMAIRCA). At first, we calculate the fuzzy relative importance between the risk factors by using the FAHP method and then we use those importance values in our proposed modified FMAIRCA to rank the failure modes according to their risk level. Our modified FMAIRCA method is computationally inexpensive and is able to provide more viable decisions. We consider a benchmark example in FMEA domain to validate the ability of our integrated approach and highlight the usefulness of the same. Further, we compare the ranking result with other MCDM methods - FVIKOR, FCOPRAS, FMOORA, FMABAC, FTOPSIS and sensitivity analysis is also performed to highlight the robustness of the proposed approach.
\end{abstract}

Index Terms - MCDM; FMEA; Risk assessment; Fuzzy AHP; Fuzzy MAIRCA.

\section{Introduction}

\subsection{Motivation}

Catastrophic failures of equipment, products, processes or services and their hazardous consequences are always a point of difficulty for every organization. These types of incidents produce a significant amount of negative impact on business reputations. Over the last few decades, organizations and 
research societies have been developing research methods to mitigate or eliminate these sudden events and if they still happen then to estimate their associated risks at the earlier stages of operation. For the first time, failure mode and effect analysis (FMEA) was officially considered as a potential safety and risk assessment tool in the 1960's by NASA [1]. Since its appearance, it has been used in a variety of industries, including military [2], nuclear [3], aerospace [4], automobile [5], manufacturing [6-8], healthcare [9], etc. The international standard IEC 60812 [10] defines FMEA as a systematic approach to analyse a system or process for identifying potential failure modes, their causes and subsequent effects on system/process performances. It is often considered as a proactive risk assessment tool widely used by quality and reliability engineers aiming to examine and eliminate the possible failures, problems and errors of the systems, processes, designs and services [11].

In any FMEA process, cross-functional experts from various domains participate, then identify, assess, prioritize and eliminate potential failure modes according to their level of criticality [12]. Traditionally, risk assessment in FMEA is performed by developing a metric known as the risk priority number (RPN). It is computed by multiplying three risk factors, namely severity (S), probability of occurrence $(\mathrm{O})$, and probability of detection $(\mathrm{D})$ for each of the failure modes [13,14]. As given in IEC 60812 [10], each of these risk factors are measured on a 10-point scale, where the greater the values of $\mathrm{S}$ and $\mathrm{O}$ the higher the severity and higher the chances of occurrence, respectively. However, $D$ is ranked in a reverse order, which implies that the higher the $\mathrm{D}$ value, the lower the detection probability of a failure mode. Therefore, the higher RPNs imply more critical failure modes and more attention to be paid for improving system performances. Actually, once the critical potential failure modes are identified, Fault Trees or Event Trees (FTA or ETA) are used to quantitatively analyse their exact probability/frequency of occurrence as well as their consequences. On the basis of the obtained results, measures can then be taken to prevent or mitigate the risks.

While the various benefits of the traditional FMEA approach are known, it has still been criticized by earlier researchers for its several drawbacks. Some of them are listed below [1]:

- Formulae for calculating RPN values are questionable.

- Duplication of RPN values and higher concentration of them at the lower end of the scale when they are plotted in a histogram diagram.

- Risk factors are assumed to be equally important.

- Risk factors are hard to be evaluated in a precise manner.

These limitations are well handled by MCDM methods $[12,15,16]$. Due to different subjective and objective constraints, it is often difficult for the cross-functional experts to precisely evaluate the failure modes with respect to each risk factor. Instead, they prefer to utilize linguistic labels to provide their opinions. Fuzzy logic methods, proposed by Zadeh [17] have been considered as a viable option when dealing with linguistic terms as they are capable of eliminating the inherent vagueness or imprecision 
within a given linguistic judgement. When fuzzy logic is integrated with MCDM approach(es) it is able to provide more viable decisions. In their work, Liu et al. $[18,19]$ provided a comprehensive review on applications of MCDM approaches in solving FMEA problems. Asan \& Soyer [20] further categorized MCDM approaches and elucidated their potentialities in solving FMEA problems.

\subsection{Related work}

\subsubsection{Recent applications of MCDM methods in FMEA}

Some recent applications of MCDM methods in solving FMEA problems are presented in Table 1.

Table 1. Some recent applications of MCDM methods to solve FMEA problems

\begin{tabular}{|c|c|c|c|c|}
\hline $\begin{array}{l}\text { MCDM } \\
\text { method }\end{array}$ & $\begin{array}{l}\text { Author(s) } \\
\text { /Year }\end{array}$ & $\begin{array}{c}\text { Variants of MCDM } \\
\text { method }\end{array}$ & Significant contribution(s) & $\begin{array}{c}\text { Application } \\
\text { domain }\end{array}$ \\
\hline \multirow{6}{*}{$\begin{array}{l}\text { Technique } \\
\text { for Order } \\
\text { Preferences } \\
\text { by Similarity } \\
\text { to Ideal } \\
\text { Solution } \\
\text { (TOPSIS) }\end{array}$} & $\begin{array}{l}\text { Song et } \\
\text { al. / } 2013 \\
{[3]}\end{array}$ & $\begin{array}{l}\text {-Entropy based weighting } \\
\text { method, } \\
\text {-Mean value method, } \\
\text { - Fuzzy Technique for } \\
\text { Order Preferences by } \\
\text { Similarity to Ideal } \\
\text { Solution (FTOPSIS). }\end{array}$ & $\begin{array}{l}\text { - Both subjective and } \\
\text { objective criteria weights } \\
\text { were taken into } \\
\text { consideration. }\end{array}$ & $\begin{array}{l}\text { - Nuclear } \\
\text { reheat valve } \\
\text { system in } \\
\text { nuclear } \\
\text { steam } \\
\text { turbine. }\end{array}$ \\
\hline & $\begin{array}{l}\text { Du et al. / } \\
2014 \text { [21] }\end{array}$ & $\begin{array}{l}\text { - Evidential Reasoning } \\
\text { (ER), } \\
\text { - TOPSIS. }\end{array}$ & $\begin{array}{l}\text {-ER was integrated with } \\
\text { TOPSIS for modelling the } \\
\text { imprecise and uncertain } \\
\text { information. }\end{array}$ & $\begin{array}{l}\text { - Ocean } \\
\text { going fishing } \\
\text { vehicle. }\end{array}$ \\
\hline & $\begin{array}{l}\text { Chang, } \\
\text { K.H./ } \\
2015 \text { [22] }\end{array}$ & - Soft-TOPSIS. & $\begin{array}{l}\text {-soft set based TOPSIS was } \\
\text { proposed and applied in } \\
\text { FMEA domain. }\end{array}$ & $\begin{array}{l}\text {-Original } \\
\text { design } \\
\text { manufacture } \\
\text { notebook } \\
\text { module } \\
\text { development. }\end{array}$ \\
\hline & $\begin{array}{l}\text { Bian et al. } \\
\text { / } 2018[4]\end{array}$ & $\begin{array}{l}\text { - D-number based } \\
\text { TOPSIS. }\end{array}$ & $\begin{array}{l}\text { - To overcome some } \\
\text { limitations of Dempster- } \\
\text { Shafer theory, D-number } \\
\text { based TOPSIS model was } \\
\text { proposed. }\end{array}$ & $\begin{array}{l}\text {-Rotor blades } \\
\text { of an aircraft } \\
\text { turbine. }\end{array}$ \\
\hline & $\begin{array}{l}\text { Carpitella } \\
\text { et al. / } \\
2018 \text { [23] }\end{array}$ & $\begin{array}{l}\text { - Consensual based AHP, } \\
\text {-FTOPSIS }\end{array}$ & $\begin{array}{l}\text { - Consensus based AHP was } \\
\text { used to derive priorities of } \\
\text { criteria. }\end{array}$ & $\begin{array}{l}- \text { Street } \\
\text { cleaning } \\
\text { vehicle. }\end{array}$ \\
\hline & $\begin{array}{l}\text { Lo et al. / } \\
2019 \text { [16] }\end{array}$ & $\begin{array}{l}\text {-Rough best-worst } \\
\text { method (RBWM), } \\
\text {-Rough TOPSIS } \\
\text { (RTOPSIS). }\end{array}$ & $\begin{array}{l}\text { - Expected cost of a failure } \\
\text { mode was considered as } \\
\text { additional criteria. } \\
\text { - An integrated approach of } \\
\text { R-BWM and R-TOPSIS was } \\
\text { presented in FMEA. }\end{array}$ & $\begin{array}{l}\text { - CNC rotary } \\
\text { and indexing } \\
\text { table. }\end{array}$ \\
\hline $\begin{array}{l}\text { COmplex } \\
\text { PRoportional } \\
\text { ASsessment } \\
\text { (COPRAS) }\end{array}$ & $\begin{array}{l}\text { Das } \\
\text { Adhikary } \\
\text { et al. / } \\
2014[24]\end{array}$ & $\begin{array}{l}\text {-Shannon's entropy } \\
\text { method, } \\
\text { - Grey COPRAS } \\
\text { (COPRAS-G) }\end{array}$ & $\begin{array}{l}\text {-Incorporated human and } \\
\text { environmental factors as } \\
\text { additional criteria, which } \\
\text { author believed has } \\
\text { significant influence on } \\
\text { failure modes. }\end{array}$ & $\begin{array}{l}\text {-Coal fired } \\
\text { thermal } \\
\text { power plant. }\end{array}$ \\
\hline
\end{tabular}




\begin{tabular}{|c|c|c|c|c|}
\hline & $\begin{array}{l}\text { Wang et } \\
\text { al. / } 2016 \\
{[25]}\end{array}$ & $\begin{array}{l}\text { - Interval valued } \\
\text { intuitionistic fuzzy } \\
\text { analytic network process } \\
\text { (IVIF-ANP), } \\
\text {-IVIF-COPRAS. }\end{array}$ & \begin{tabular}{lcr}
\multicolumn{2}{c}{ Proposed } & an integrated \\
MCDM & approach & by \\
combining & IVIF-ANP & $\&$ \\
COPRAS. & & \\
\end{tabular} & $\begin{array}{l}\text {-Hospital } \\
\text { service } \\
\text { diagnosis. }\end{array}$ \\
\hline \multirow[b]{2}{*}{$\begin{array}{l}\text { VIsekriteriju } \\
\text { mska } \\
\text { optimizacija i } \\
\text { KOmpromis } \\
\text { no Resenje } \\
\text { (VIKOR) }\end{array}$} & $\begin{array}{l}\text { Wang et } \\
\text { al. / } 2018 \\
{[5]}\end{array}$ & $\begin{array}{l}\text {-House of reliability } \\
\text { (HoR), } \\
\text {-Rough VIKOR. }\end{array}$ & $\begin{array}{l}\text {-By applying HoR, } \\
\text { dependency among different } \\
\text { failure modes and the link } \\
\text { between the risk factors were } \\
\text { established. }\end{array}$ & $\begin{array}{l}\text { - } \\
\text { Transmission } \\
\text { system of a } \\
\text { vertical } \\
\text { machining } \\
\text { centre. }\end{array}$ \\
\hline & $\begin{array}{l}\text { Tian et al. } \\
\text { / } 2018[6]\end{array}$ & $\begin{array}{l}\text { - Fuzzy BWM, } \\
\text { - Fuzzy proximity and } \\
\text { fuzzy similarity entropy } \\
\text { weights, } \\
\text {-Fuzzy VIKOR }\end{array}$ & $\begin{array}{l}\text {-To derive the risk factors, } \\
\text { fuzzy BWM method was } \\
\text { employed, } \\
\text {-To obtain the weights of } \\
\text { FMEA team members, a } \\
\text { comprehensive structure was } \\
\text { developed, using fuzzy } \\
\text { proximity entropy weights } \\
\text { and fuzzy relative entropy } \\
\text { weights. }\end{array}$ & $\begin{array}{l}\text {-Grinding } \\
\text { wheel system }\end{array}$ \\
\hline \multirow{2}{*}{$\begin{array}{l}\text { ELimination } \\
\text { Et Choix } \\
\text { Traduisant la } \\
\text { REalité } \\
\text { (ELECTRE) }\end{array}$} & $\begin{array}{l}\text { Liu et al. / } \\
2016[26]\end{array}$ & $\begin{array}{l}\text {-Interval two-tuple } \\
\text { linguistic ELECTRE }\end{array}$ & $\begin{array}{l}\text {-Both subjective and } \\
\text { objective weights were } \\
\text { considered }\end{array}$ & $\begin{array}{l}\text {-Proton beam } \\
\text { radiotherapy. }\end{array}$ \\
\hline & $\begin{array}{l}\text { Antonella } \\
\text { et al. / } \\
2017[12]\end{array}$ & $\begin{array}{l}\text { - ELECTRE-TRI based } \\
\text { approach }\end{array}$ & $\begin{array}{l}\text {-ELECTRE-TRI based } \\
\text { approach was used to } \\
\text { classify the failure modes. }\end{array}$ & $\begin{array}{l}\text {-Diary } \\
\text { industry }\end{array}$ \\
\hline \multirow{3}{*}{$\begin{array}{l}\text { MULTIplicat } \\
\text { ive form of } \\
\text { Multi } \\
\text { Objective } \\
\text { Optimization } \\
\text { by Ratio } \\
\text { Analysis } \\
\text { (MULTIMO } \\
\text { ORA) }\end{array}$} & $\begin{array}{l}\text { Liu et } \\
\text { al./2014 } \\
{[27]}\end{array}$ & - Fuzzy MULTIMOORA & $\begin{array}{l}\text { - Application of fuzzy } \\
\text { MULTIMOORA in FMEA } \\
\text { domain. }\end{array}$ & $\begin{array}{l}\text {-Healthcare } \\
\text { sector }\end{array}$ \\
\hline & $\begin{array}{l}\text { Zhao et } \\
\text { al./2017 } \\
{[28]}\end{array}$ & $\begin{array}{l}\text {-IVIF-Continuous } \\
\text { weighted entropy method, } \\
\text {-IVIF-MULTIMOORA }\end{array}$ & $\begin{array}{l}\text { - IVIF-MULTIMOORA was } \\
\text { developed and combined } \\
\text { with IVIF-continuous } \\
\text { weighted entropy method }\end{array}$ & $\begin{array}{l}\text { - Steel } \\
\text { production } \\
\text { process risk } \\
\text { management. }\end{array}$ \\
\hline & $\begin{array}{l}\text { Fattahi \& } \\
\text { Khalilzad } \\
\text { eh / } 2018 \\
{[29]}\end{array}$ & $\begin{array}{l}\text {-Fuzzy AHP, } \\
\text {-Fuzzy MULTIMOORA }\end{array}$ & $\begin{array}{l}\text {-Weights of each failure } \\
\text { modes were calculated by } \\
\text { using three factors - time, } \\
\text { cost and profit. }\end{array}$ & $\begin{array}{l}\text {-Steel } \\
\text { industry. }\end{array}$ \\
\hline $\begin{array}{l}\text { Multi- } \\
\text { Attribute } \\
\text { Border } \\
\text { Approximati } \\
\text { on and } \\
\text { Comparison } \\
\text { (MABAC) } \\
\end{array}$ & $\begin{array}{l}\text { Liu et al. / } \\
2019[30]\end{array}$ & - IVIF MABAC & $\begin{array}{l}\text { - Developed a linear } \\
\text { programming model for } \\
\text { obtaining the optimal } \\
\text { weights of risk factors when } \\
\text { the prior weight information } \\
\text { is incomplete. }\end{array}$ & $\begin{array}{l}\text { - Healthcare } \\
\text { sector }\end{array}$ \\
\hline $\begin{array}{l}\text { Election } \\
\text { based on } \\
\text { Relative } \\
\text { Value } \\
\text { Distance } \\
\text { (ERVD) }\end{array}$ & $\begin{array}{l}\text { Gugaliya } \\
\text { et al. / } \\
2019[31]\end{array}$ & $\begin{array}{l}\text { - AHP } \\
\text { - ERVD }\end{array}$ & $\begin{array}{l}\text { - A new MCDM method } \\
\text { based on Prospect Theory - } \\
\text { ERVD was applied in } \\
\text { FMEA. } \\
\text { - A detailed FMEA of } \\
\text { induction motor was carried } \\
\text { out }\end{array}$ & $\begin{array}{l}\text { - Induction } \\
\text { motor. }\end{array}$ \\
\hline
\end{tabular}




\subsubsection{Literature related to AHP}

AHP is considered as one of the more commonly used decision making tools among most of the researchers and industries, first proposed by Satty [32]. It has been applied in a wide range of application contexts related to MCDM problems [33]. It is a weighted factor scoring model and has capability to incorporate inherent inconsistencies of a decision making process. The classical AHP considers the crisp judgements of decision makers but is not able to include their vague thoughts [34-36]. In a decision-making process, it is not possible for the decision makers to exactly evaluate the conflicting criteria and alternatives. Thus, experts may favour intermediate judgements rather than definitive ones. Fuzzy logic theory proposed by Zadeh [17] is a viable alternative to cope with this kind of problem. Although there are some recent advancements of fuzzy logic theory (i.e., type-2 fuzzy sets, interval fuzzy sets, etc.), it is still now widely accepted, is mathematically simpler and can provide a solid basis for rational decisions for most of the complex MCDM problems. Laarhoven \& Pedrycz [37] was first to extend the crisp AHP into the fuzzy domain. Their computation steps were the same as presented by Satty [32]. A Logarithmic least square method was used to derive fuzzy weights and fuzzy performance scores. Later, Buckley [38] presented the concept of fuzzy priorities of comparison ratios, whose membership functions were trapezoidal. Buckley [38] claimed that linear equations presented in [37] do not have unique solutions all the time and that some of the obtained solutions were not triangular fuzzy numbers. Thus, he used the geometric mean method to derive fuzzy weights and performance scores. Chang [39] developed an extent analysis method for fuzzy AHP. The main concept was the extent of an alternative for satisfying the decision goal. However, till now, Buckley's fuzzy AHP has not received much criticism and thus we prefer to use that approach in our present work.

\subsubsection{Literature related to Multi Attribute Ideal Real Comparative Analysis (MAIRCA)}

MAIRCA is a newly developed MCDM method developed by the Centre for Logistic Research of Defence University of Belgrade by Pamučar et al. [40]. This method has been proven to be stable over other popular MCDM methods, like TOPSIS or ELECTRE. It uses a simple mathematical algorithm, and the possibility to combine it with other methods makes it a viable option for further investigation and development. In [40], it was combined with fuzzy DEMATEL (Decision Making Trial and Evaluation Laboratory) for railway level crossing selection. Gigovic et al. [41] combined DEMATEL and ANP (Analytic Network Process) with MAIRCA to select a site for an ammunition depot. In another work, Pamučar et al. [42] proposed the interval rough MAIRCA (IR-MAIRCA) and combined it with IR DEMATEL-ANP (IR'DANP). They validated their approach by considering an example of the bidder selection problem. Chatterjee et al. [43] elucidated the concept of rough MAIRCA (R'MAIRCA) and combined it with rough DEMATEL-ANP (R'AMATEL) which was validated by citing an example of the green supply chain selection problem. Pamucar et al. [44] proposed a framework by combining the fuzzy DEMATEL-MAIRCA approach for sustainable multimodal logistic centre selection. 
Recently, Pamucar et al. [45] further extended the concept of MAIRCA into the interval valued fuzzy rough number domain for more improvised decision making.

\subsection{Contributions to the existing literature}

From the above discussion, the following points can be summarized which highlight the motivations and contributions of our present work to the existing literature of FMEA:

- The theoretical motivations of this work support the risk analyst with a simple but reliable decision making approach for performing the FMEA task. Calculating the relative importance of the risk factors is considered as a necessary task in FMEA, as they are dependent on each other. Till date, we observe several applications of the AHP method and its variants in the FMEA domain [23,31,34]. The work carried out by Kutlu and Ekmekçioğlu [34] highlighted the application of fuzzy AHP and the use of Chang's extent analysis method [39]. However this approach has received several criticisms. Wang et al. [46] in their analysis highlighted that "the extent analysis method cannot estimate the true weights from a fuzzy comparison matrix and has led to quite a number of misapplications in the literature". They also pointed out that use of the extent analysis method to fuzzy AHP problems may lead to a wrong decision. As mentioned earlier, the fuzzy AHP proposed by Buckley [38] has not received much criticism, and so we used this approach in our present work. Further, in [34], we observe that de-fuzzified risk factor weights obtained from fuzzy AHP were utilized for prioritizing the failure modes according to their level of risk. We believe that applying such de-fuzzification processes at the earlier stages may cause a substantial amount of losses in the inherent information within a fuzzy number and may lead to wrong decision making.

- Apart from the earlier mentioned advantages of the MAIRCA method, its relevancy and necessity of application in FMEA domain are presented below:

a) It is most often observed that in a complex FMEA problem, it becomes necessary to deal with a large number of failure modes. Moreover, in some industrial practices, multiple case-specific risk factors are considered for more viable risk estimation related to each failure mode. MAIRCA is considered as a suitable option for MCDM problems when the number of alternatives and criteria are higher.

b) It is often necessary to include or exclude a failure mode during a FMEA process. In such situations, we observe that most of the earlier used MCDM approaches incur rank reversal phenomenon which creates confusion among the risk analyst. After several experiments we observed that the MAIRCA approach does not incur any rank reversal phenomenon in such cases.

c) While considering multiple risk factors for the risk estimation process, some of the indices are quantitative and some are qualitative in nature. MAIRCA is able to incorporate both types of criteria in the decision-making process. 
d) Like the TOPSIS approach, it is also based on the concept of ideal and anti-ideal solutions. However the major advantage of this approach over the earlier ones is that equal preferences are given to each alternative, or in the other sense, decision makers are unbiased towards selecting an alternative.

We notice from the earlier discussion that until now no literature is present in the FMEA domain based on the application of the MAIRCA approach. Apart from that, in all of the above MAIRCA applications, the authors did not pay much attention to reduce the hard computational efforts or computational steps of their methods. In all of them, they used the linear max-min normalization technique, which is rather simpler and has robust mathematical foundation, but we say that when the numbers of alternatives are increased, a large number of comparisons are to be made among the input values to find the maximum and minimum one. We do agree that some advanced versions of MAIRCA aiming to incorporate the more imprecision or vagueness are present in the literature, but as Ribeiro [47] said, "too much fuzzification does not imply better modelling of reality, it can be counter-productive", we only considered fuzzy MCDM in this paper. In brief, we present a modified MAIRCA method coupled with fuzzy AHP and validated our approach by solving the benchmark example of FMEA presented in [34]. We observe that solution stability of our proposed approach is more robust than the method used in [34].

\subsection{Overview}

The rest of the paper is organized as follows: in Section 2 we present the basic concepts of fuzzy logic and fuzzy numbers. Next, in Section 3, we enumerate our proposed integrated approach for ranking the failure modes according to their risk levels. In Section 4, we reproduce a benchmark example of FMEA and solve it by our approach. Validation and discussions of the obtained results are presented in Section 5 , whereas Section 6 highlights the managerial implications of our proposed approach in FMEA literature along with the conclusion.

\section{Preliminaries}

Fuzzy set theory was introduced by Zadeh [17] to overcome the inherent vagueness involved in various decision making aspects. A fuzzy set $A^{\sim}$ can be defined mathematically by a membership function $\mu_{A} \sim(x)$, which assigns each element $x$ in the universe of discourse $X$ to a real number in the interval $[0,1]$.

A fuzzy number is a fuzzy subset in the universe of discourse $X$, which is both convex and normal. A fuzzy set $\tilde{A}$ in the universe of discourse $X$ is convex if and only if for all $x_{1}, x_{2}$ in $X, \mu_{A} \sim\left(\lambda x_{1}+\right.$ $\left.(1-\lambda) x_{2}\right) \geq \min \left(\mu_{\tilde{A}}\left(x_{1}\right), \mu_{\tilde{A}}\left(x_{2}\right)\right)$, where $\lambda \in[0,1]$. The similar fuzzy set $A^{\sim}$ is called a normal fuzzy set if $\exists x_{i} \in X, \mu_{\tilde{A}}\left(x_{i}\right)=1$. 
There are different types of fuzzy numbers and among them the triangular fuzzy number (TFN) has been mostly used for its intuitiveness and computationally efficient representation. A TFN is represented by a triplet $\tilde{A}=\left[a_{l}, a_{m}, a_{u}\right]$, which is further depicted in Figure 1. Membership function of a TFN is defined as:

$$
\mu_{\tilde{A}}(x)=\left\{\begin{array}{cl}
\frac{x-a_{l}}{a_{m}-a_{l}} & , a_{l} \leq x \leq a_{m} \\
\frac{x-a_{u}}{a_{m}-a_{l}} & , a_{m} \leq x \leq a_{u} \\
0 & , \text { otherwise }
\end{array}\right.
$$

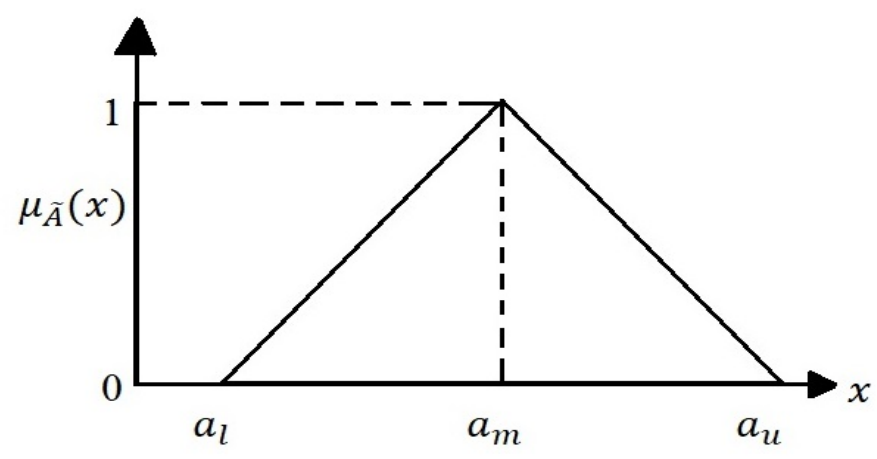

Figure 1. Graphical representation of a TFN

Arithmetic operations on two fuzzy numbers $\widetilde{A}=\left[a_{l}, a_{m}, a_{u}\right]$, and $\widetilde{B}=\left[b_{l}, b_{m}, b_{u}\right]$, where $a_{l} \leq$ $a_{m} \leq a_{u}$ and $b_{l} \leq b_{m} \leq b_{u}$ are elucidated below:

Addition:

$$
\tilde{A} \oplus \tilde{B}=\left[a_{l}, a_{m}, a_{u}\right] \oplus\left[b_{l}, b_{m}, b_{u}\right]=\left[a_{l}+b_{l}, a_{m}+b_{m}, a_{u}+b_{u}\right]
$$

Subtraction: $\quad \tilde{A} \ominus \tilde{B}=\left[a_{l}, a_{m}, a_{u}\right] \ominus\left[b_{l}, b_{m}, b_{u}\right]=\left[a_{l}-b_{u}, a_{m}-b_{m}, a_{u}-b_{l}\right]$

Multiplication: $\tilde{A} \otimes \tilde{B}=\left[a_{l}, a_{m}, a_{u}\right] \otimes\left[b_{l}, b_{m}, b_{u}\right]=\left[a_{l} \times b_{l}, a_{m} \times b_{m}, a_{u} \times b_{u}\right]$,

$$
\text { if } a_{l} \geq 0 \text { and } b_{l} \geq 0 \text {. }
$$

\section{Division:}

$$
\tilde{A} \oslash \tilde{B}=\left[a_{l}, a_{m}, a_{u}\right] \oslash\left[b_{l}, b_{m}, b_{u}\right]=\left[\frac{a_{l}}{b_{u}}, \frac{a_{m}}{b_{m}}, \frac{a_{u}}{b_{l}}\right], \text { if } a_{l} \geq 0 \text { and } b_{l}>0
$$

\section{Multiplication}

by a scalar, $k$ :

$$
k \otimes \tilde{A}=\left\{\begin{array}{l}
\left(k a_{l}, k a_{m}, k a_{u}\right), \text { if } k>0 \\
\left(k a_{u}, k a_{m}, k a_{l}\right), \text { if } k<0
\end{array}\right.
$$

Generally triangular fuzzy numbers are considered as the extended form of a trapezoidal fuzzy number. A trapezoidal fuzzy number $\tilde{A}$ is defined by a quadruplet $\tilde{A}=\left(a_{l}, a_{m 1}, a_{m 2}, a_{u}\right)$. Arithmetic operations of two trapezoidal fuzzy numbers are almost similar to that of triangular fuzzy numbers and interested readers are requested to refer to the work of Krohling \& de Souza [48] for detailed information. 
Fuzzy numbers often need to be transformed into a crisp number for several purposes, such as comparison, ranking, etc. Such transformation methods are known as de-fuzzification [49]. There are several popular methods available for this purpose, and among them the graded mean average is the most popular one, due to its simple calculation step and robust mathematical foundation, which is represented by Eq. 7 and 8 .

$$
\begin{gathered}
A=\frac{a_{l}+4 a_{m}+a_{u}}{6} \text { (for triangular fuzzy number) } \\
A=\frac{a_{l}+2 a_{m 1}+2 a_{m 2}+a_{u}}{6} \text { (for trapezoidal fuzzy number) }
\end{gathered}
$$

\section{Proposed integrated approach}

The complete approach is made up of the following three major steps. However, the workflow diagram of our proposed approach is given in Fig. 2.

- Structuring of the problem

- Calculation of criteria weights

- Ranking of failure modes according to their level of criticality

In the ensuing sub-sections, we elaborate on the above steps.

\subsection{Structuring of the problem}

The following steps are carried out to structure the problem. At the very initial stage of any decisionmaking process, decision makers should have a fair idea about the goal. In this study, our major aim is to select the most critical failure mode by means of our proposed integrated MCDM approach. After that, top management choose cross-functional experts who have a fair idea about the alternatives (in our case failure modes). Later, these experts identify the evaluating criteria for the selection process. They also choose/select proper linguistic scales to rate the criteria and alternatives.

\subsection{Calculation of criteria weights}

In this sub-section we reproduce the calculation steps of fuzzy AHP given in [38].

Step 1. With the advice of the experts, we build the pairwise comparison matrices for the criteria/subcriteria using linguistic terms. Suppose there are $k$ cross-functional experts who participate in the decision-making process. Each element $\tilde{a}_{i j}^{k}$ of the pairwise comparison matrix $\tilde{A}^{k}$ is a fuzzy number corresponding to the linguistic term. The pairwise comparison matrix is given by Eq. (9):

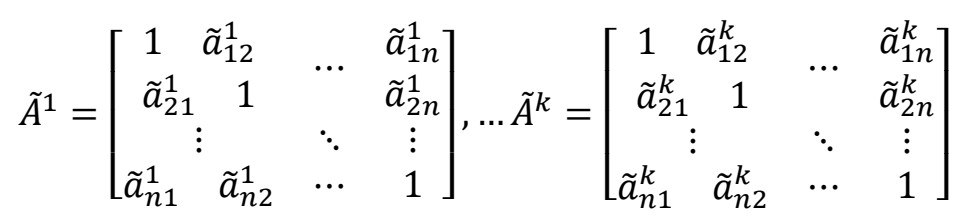


Step 2. Calculate the aggregated fuzzy pairwise comparison matrix as shown in Eq. (10).

$$
\begin{aligned}
& \tilde{A}=\left[\begin{array}{cccc}
1 & \tilde{a}_{12}^{1} \oplus \ldots \oplus \tilde{a}_{12}^{k} & & \frac{\tilde{a}_{1 n}^{1} \oplus \ldots \oplus \tilde{a}_{1 n}^{k}}{k} \\
\frac{\tilde{a}_{21}^{1} \oplus \ldots \oplus \tilde{a}_{21}^{k}}{k} & \frac{1}{k} & & \frac{\tilde{a}_{2 n}^{1} \oplus \ldots \oplus \tilde{a}_{2 n}^{k}}{k} \\
\frac{\tilde{a}_{n 1}^{1} \oplus \ldots \oplus \tilde{a}_{n 1}^{k}}{k} & \frac{\tilde{a}_{n 2}^{1} \oplus \ldots \oplus \tilde{a}_{n 2}^{k}}{k} & \cdots & \vdots \\
\frac{1}{k} & & & 1
\end{array}\right] \\
& \text { Or, } \\
& \tilde{A}=\left[\begin{array}{cccc}
1 & \left(a_{l 12}, a_{m 12}, a_{u 12}\right) & \ldots & a_{l 1 n}, a_{m 1 n}, a_{u 1 n} \\
\left(a_{l 21}, a_{m 21}, a_{u 21}\right) & 1 & \ddots & a_{l 2 n}, a_{m 2 n}, a_{u 2 n} \\
\left(a_{l n 1}, a_{m n 1}, a_{u n 1}\right) & \left(a_{l n 2}, a_{m n 2}, a_{u n 2}\right) & \ldots & \vdots
\end{array}\right]
\end{aligned}
$$

Step 3. Next, we check the consistency of the fuzzy aggregated pairwise comparison matrix $\tilde{A}=\left[\tilde{a}_{i j}\right]$ by defuzzifying the pairwise comparison values, using the graded mean integration approach (refer Eq. 7). If $\tilde{A}=\left[\tilde{a}_{i j}\right]$ is a fuzzy positive reciprocal matrix and $A=\left[a_{i j}\right]$ is the defuzzified positive reciprocal matrix, then $\tilde{A}$ is said to be consistent iff $A$ is consistent [38]. The general procedures for measuring the consistency ratio in AHP is given in [31]. If, in case the result is not consistent, experts need to reevaluate the pairwise comparisons.

Step 4. For weighing the criteria, the fuzzy geometric mean for each row of the matrix is calculated as shown in Eq. (11). First, fuzzy geometric means of the first parameters of the triangular fuzzy numbers in each row are calculated as follows:

$$
\begin{aligned}
& a_{l 1}=\left[1 \times a_{l 12} \times \ldots \times a_{l 1 n}\right]^{\frac{1}{n}} \\
& a_{l 2}=\left[a_{l 21} \times 1 \times \ldots \times a_{l 2 n}\right]^{\frac{1}{n}} \\
& a_{l i}=\left[a_{l n 1} \times a_{l n 2} \times \ldots \times 1\right]^{\frac{1}{n}}
\end{aligned}
$$

Similarly, we calculate the geometric means of second and third parameters of the triangular fuzzy numbers in every row.

Step 5. Let us now assume that the sums of the geometric mean values in the row are $a_{l s}, a_{m s}$, and $a_{u s}$ respectively, then fuzzy criteria weights are calculated as Eq. (12). 


$$
\begin{aligned}
& \widetilde{w}_{1}\left(\frac{a_{l 1}}{a_{u s}}, \frac{a_{m 1}}{a_{m s}}, \frac{a_{u 1}}{a_{l s}}\right) \\
& \widetilde{W}=\underset{\vdots}{\widetilde{w}_{2}}=\left(\frac{a_{l 2}}{a_{u s}}, \frac{a_{m 2}}{a_{m s}}, \frac{a_{u 2}}{a_{l s}}\right) \\
& \widetilde{w}_{n} \quad\left(\frac{a_{l n}}{a_{u s}}, \frac{a_{m n}}{a_{m s}}, \frac{a_{u n}}{a_{l s}}\right)
\end{aligned}
$$

After calculating the criteria weights in the next subsection, we enumerate the steps involved in our proposed FMAIRCA approach.

\subsection{Fuzzy MAIRCA for ranking of alternatives}

In the following steps, we describe our proposed FMAIRCA approach.

Step 1. Based on the linguistic evaluation of alternatives with respect to the considered criteria, the initial linguistic decision matrix (D_L) is constructed. For the sake of generality, let us consider that $\mathrm{k}$ number of experts are participating in the evaluation process of $m$ alternatives with respect to $n$ number of criteria. The obtained decision matrix is presented by Eq. (13),

$$
D_{L}=\left(\begin{array}{cccc}
L_{11}^{1}, \ldots L_{11}^{k} & L_{12}^{1}, \ldots L_{12}^{k} & \ldots & L_{1 n}^{1}, \ldots L_{1 n}^{k} \\
L_{21}^{1}, \ldots L_{21}^{k} & L_{22}^{1}, \ldots L_{22}^{k} & \ldots & L_{2 n}^{1}, \ldots L_{2 n}^{k} \\
\vdots & \ddots & & \vdots \\
\vdots & \ddots & & \vdots \\
L_{m 1}^{1}, \ldots L_{m 1}^{k} & L_{m 2}^{1}, \ldots L_{m 2}^{k} & \ldots & L_{m n}^{1}, \ldots L_{m n}^{k}
\end{array}\right) .
$$

Here, $L_{m n}^{k}$ implies that the $m-t h$ alternative is linguistically evaluated with respect to the $n-t h$ criterion by the $k-t h$ decision maker.

Step 2. Following the scale for rating alternatives by means of fuzzy numbers, each of the linguistic decisions are replaced by respective fuzzy numbers as represented by Eq. (14),

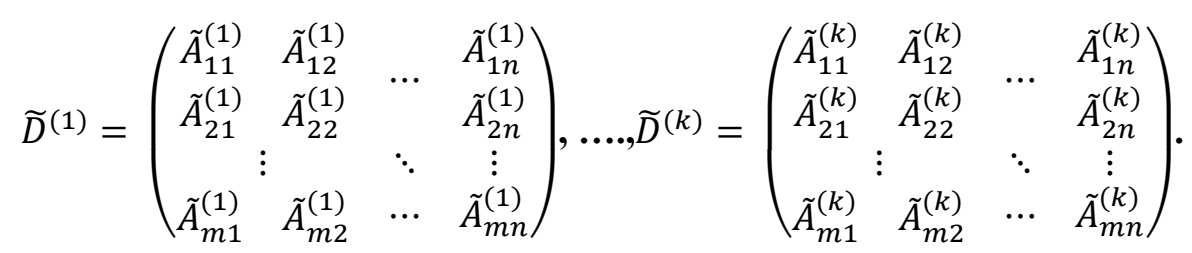

Step 3. Next, by using Eq. (6), we construct the fuzzy aggregated decision matrix as represented by Eq. (15).

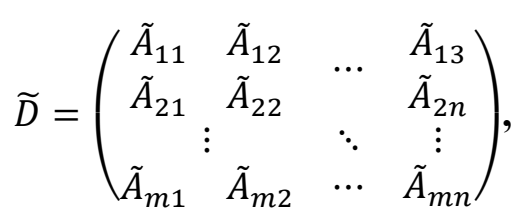




$$
\text { Where } \widetilde{A}_{11}=\frac{\tilde{A}_{11}^{(1)}+\tilde{A}_{11}^{(2)}+\cdots+\tilde{A}_{11}^{(k)}}{k} \text {. }
$$

Step 4. In this step, we define the preferences according to the selection of alternatives $P_{A_{i}}$. This step implies that the decision maker is un-biased towards the selection of an alternative. Since any alternative can be chosen with equal probability, the preferences for each of them can be represented by Eq. (16).

$$
P_{A_{i}}=\frac{1}{m} ; \sum_{i=1}^{m} P_{A_{i}}=1
$$

Step 5. Elements of the fuzzy theoretical evaluation matrix $\left(\tilde{T}_{P_{A}}\right)$ are calculated by multiplying preferences according to alternatives $P_{A_{i}}$ and fuzzy criteria weights obtained by using FAHP, as shown in Eq. (17).

$$
\widetilde{T}_{P_{A}}=\left(\begin{array}{ccccc}
\frac{1}{m} \widetilde{w}_{1} & \frac{1}{m} \widetilde{w}_{2} & & \frac{1}{m} \widetilde{w}_{n} \\
\frac{1}{m} \widetilde{w}_{1} & \frac{1}{m} \widetilde{w}_{2} & & \frac{1}{m} \widetilde{w}_{n} \\
& \vdots & \ddots & \vdots \\
\frac{1}{m} \widetilde{w}_{1} & \frac{1}{m} \widetilde{w}_{2} & \cdots & \frac{1}{m} \widetilde{w}_{n}
\end{array}\right)=\left(\begin{array}{ccccc}
\tilde{t}_{p 11} & \tilde{t}_{p 12} & & \tilde{t}_{p n 1} \\
\tilde{t}_{p 21} & \tilde{t}_{p 22} & \cdots & \tilde{t}_{p n 2} \\
& \vdots & \ddots & \vdots \\
\tilde{t}_{p m 1} & \tilde{t}_{p m 2} & \cdots & \tilde{t}_{p m n}
\end{array}\right)
$$

Step 6. In this step we normalize the fuzzy aggregated decision matrix as obtained in step 3 and generate the fuzzy normalized decision matrix $\widetilde{N}$. The normalization procedure of the decision matrix is carried out to increase its comparable capability. We use a new type of normalization technique as shown in Eq. (18) in FMAIRCA to reduce the complexity involved in hard computation as well as to improve the accuracy of numeration. Another benefit of using this procedure is that the decision-maker need not be concerned about the nature of the criteria (i.e., benefit or cost criteria). Generally, these types of situations are frequently encountered when the decision-maker is used to dealing with large numbers of conflicting criteria.

$$
\begin{aligned}
& n_{i j}^{l}=\frac{a_{i j}^{l}}{\sqrt{\sum_{i=1}^{m}\left[\left(a_{i j}^{l}\right)^{2}+\left(a_{i j}^{m}\right)^{2}+\left(a_{i j}^{u}\right)^{2}\right]}} \\
& n_{i j}^{m}=\frac{a_{i j}^{m}}{\sqrt{\sum_{i=1}^{m}\left[\left(a_{i j}^{l}\right)^{2}+\left(a_{i j}^{m}\right)^{2}+\left(a_{i j}^{u}\right)^{2}\right]}} \\
& n_{i j}^{u}=\frac{a_{i j}^{u}}{\sqrt{\sum_{i=1}^{m}\left[\left(a_{i j}^{l}\right)^{2}+\left(a_{i j}^{m}\right)^{2}+\left(a_{i j}^{u}\right)^{2}\right]}}
\end{aligned}
$$

Step 7. Next, we calculate the fuzzy elements of the actual ponder matrix $\left(\widetilde{T}_{r_{A}}\right)$. This step is carried out by multiplying the elements of the normalized decision matrix to the elements of the matrix of actual ponder by using Eq. (19). 


$$
\begin{aligned}
& \tilde{T}_{r_{A}}=\left(\begin{array}{cccc}
\tilde{t}_{r 11} & \tilde{t}_{r 12} & & \tilde{t}_{r n 1} \\
\tilde{t}_{r 21} & \tilde{t}_{r 22} & \cdots & \tilde{t}_{r n 2} \\
& \vdots & \ddots & \vdots \\
\tilde{t}_{r m 1} & \tilde{t}_{r m 2} & \cdots & \tilde{t}_{r m n}
\end{array}\right)
\end{aligned}
$$

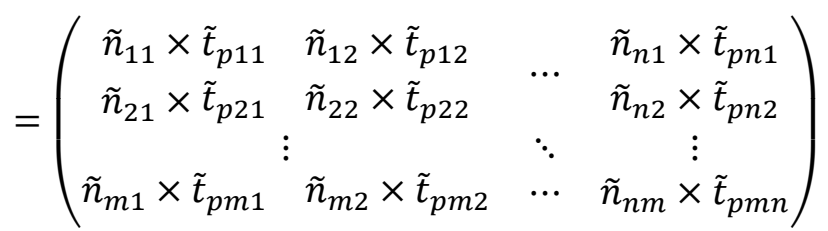

Step 8. In this step we calculate the gap between the theoretical and actual evaluation of each alternative with respect to each criterion. In other works [40-45], the authors suggested to subtract $\widetilde{T}_{P_{A}}$ with $\widetilde{T}_{r_{A}}$ and to obtain the total gap matrix $\tilde{G}$. It is preferable that the best ranked alternative should have minimum gap value with respect to each criteria. After obtaining the gap value they are further defuzzified to obtain the crisp gap value. To reduce the computational steps and to directly obtain the gap values we carry out those steps in the following way.

We use the distance measurement formulae between two fuzzy numbers as given in [34]. The reason for using this may be supplemented as it is a well-established technique in MCDM approaches (e.g., FTOPSIS). Thus, elements of total gap matrix are calculated by using Eq. (20):

$$
g_{i j}=\sqrt{\frac{1}{3}\left[\left(t_{p i j_{l}}-t_{r i j_{l}}\right)^{2}+\left(t_{p i j_{m}}-t_{r i j_{m}}\right)^{2}+\left(t_{p i j_{u}}-t_{r i j_{u}}\right)^{2}\right]}
$$

Step 9. Next, we sum the gap values for each alternative with respect to each criterion and obtain the final value of the criteria functions by using Eq. (21). The criteria functions are then arranged in ascending order and finally preferences are ranked.

$$
Q_{i}=\sum_{j=1}^{n} g_{i j}, \text { where } i=1,2, \ldots, m
$$




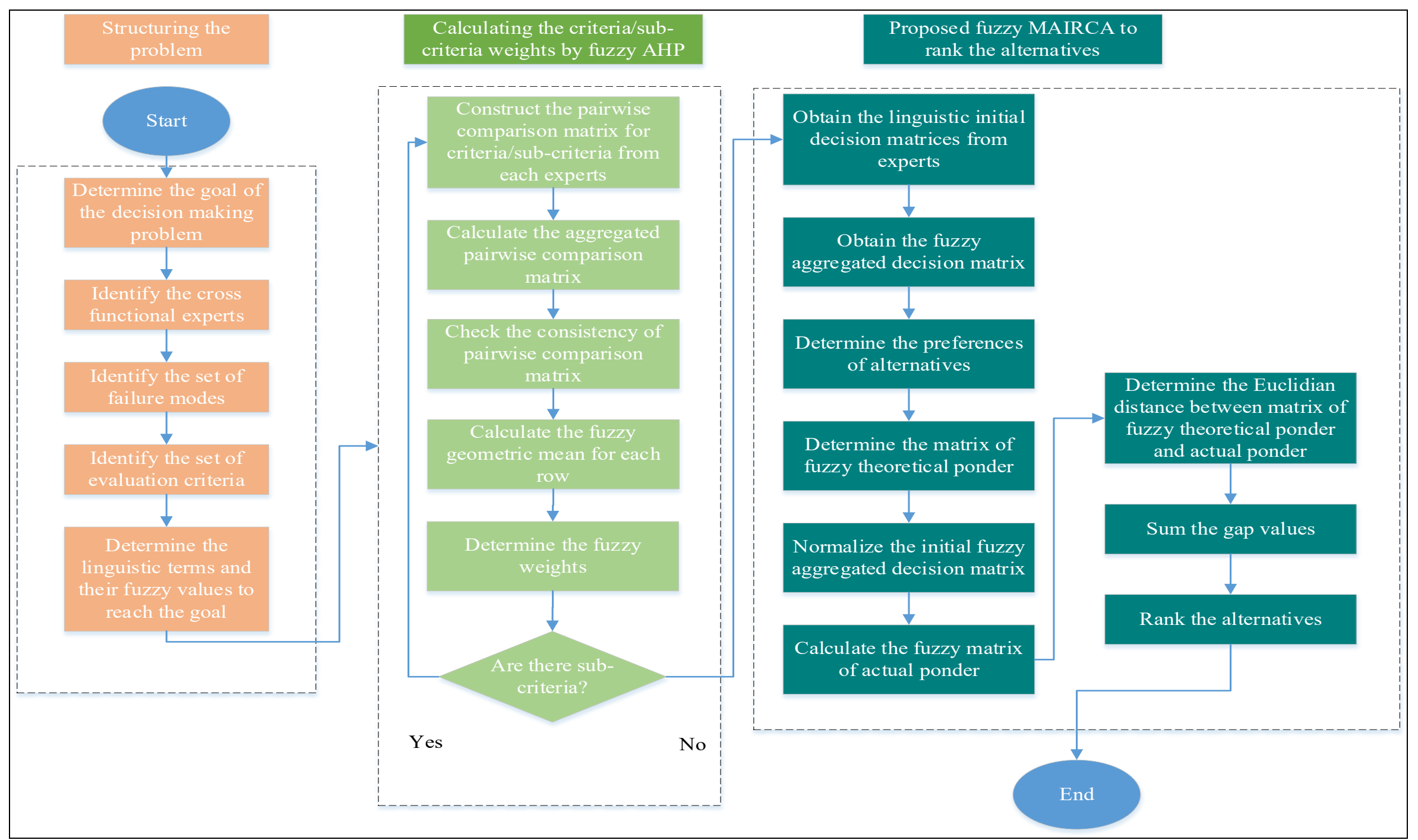

Figure 2. Flow diagram of the proposed integrated MCDM approach 


\section{Application of proposed approach for failure modes ranking of FMEA}

Application of the proposed approach is supplemented by solving a well-known example presented in [34]. In that example, a total of eight numbers of failure modes were considered as follows - nonconforming materials (FM1), wrong die (FM2), wrong program (FM3), excessive cycle time (FM4), wrong process (FM5), damaged goods (FM6), wrong part (FM7), and incorrect forms (FM8). Three experts (let us assume they are known as DM1, DM2 and DM3), with equal relative importance, were involved in the FMEA team to evaluate the relative importance among the risk factors $-\mathrm{S}, \mathrm{O}$ and $\mathrm{D}$ by the FAHP process. In their work, they used the FAHP process based on the extent analysis method proposed by Chang [39]. As already highlighted in the previous section, the FAHP method based on extent analysis has received several criticisms and thus we use the method proposed by [38]. We have already presented the steps involved to calculate the criteria weights in subsection 3.2 by using Eq. (9)-(12). We use the same scale as given in [34], but for the readers benefit we present them in Table 2 (for criteria weight evaluation), and Table 4 (for prioritizing the failure modes). The fuzzy criteria weights are calculated by using the linguistic evaluations given in Table 3 and final fuzzy values are shown in Table 4 . The consistency ratio (CR) of the pairwise comparison matrix is 0.050 , which is less than 0.10 . Thus, the calculated weights are consistent [31].

\begin{tabular}{|c|c|}
\hline Absolutely strong (AS) & $(2,5 / 2,3)$ \\
\hline Very strong (VS) & $(3 / 2,2,5 / 2)$ \\
\hline Fairly strong (FS) & $(1,3 / 2,2)$ \\
\hline Slightly strong (SS) & $(1,1,3 / 2)$ \\
\hline Equal $(\mathrm{E})$ & $(1,1,1)$ \\
\hline Slightly weak (SW) & $(2 / 3,1,1)$ \\
\hline Fairly weak (FW) & $(1 / 2,2 / 3,1)$ \\
\hline Very weak (VW) & $(2 / 5,1 / 2,2 / 3)$ \\
\hline Absolutely weak (AW) & $(1 / 3,2 / 5,1 / 2)$ \\
\hline
\end{tabular}

Table 3. Linguistic evaluations for obtaining criteria weights

\begin{tabular}{|c|c|c|c|c|c|c|c|c|c|}
\hline & \multicolumn{3}{|c|}{ Severity } & \multicolumn{3}{c|}{ Occurrence } & \multicolumn{3}{c|}{ Detection } \\
\cline { 2 - 10 } & DM1 & DM2 & DM3 & DM1 & DM2 & DM3 & DM1 & DM2 & DM3 \\
\hline Severity & E & E & E & FS & FS & VS & SS & SS & SS \\
\hline Occurrence & - & - & - & E & E & E & SS & FW & E \\
\hline Detection & - & - & - & - & - & - & E & E & E \\
\hline
\end{tabular}

Table 4. Fuzzy weights of the risk factors

\begin{tabular}{|c|c|}
\hline Criteria & Fuzzy weights \\
\hline$\widetilde{w}_{S}$ & $(0.293,0.388,0.565)$ \\
\hline$\widetilde{w}_{O}$ & $(0.203,0.267,0.386)$ \\
\hline$\widetilde{w}_{D}$ & $(0.234,0.345,0.420)$ \\
\hline
\end{tabular}


Next, we start prioritizing the failure modes by using Eqs. (13) - (21), presented in sub-section 3.3. We obtain the fuzzy aggregated decision matrix (mathematically represented by Eq. (15)) as shown in Table 7, from Table 5 and 6 and by using Eq. (13)-(14).

Table 5. Fuzzy evaluation scores to rate the failure modes

\begin{tabular}{|c|c|}
\hline Linguistic terms & Fuzzy score \\
\hline Very poor (VP) & $\mathbf{( 0 , 0 , 1 )}$ \\
\hline Poor (P) & $\mathbf{( 0 , 1 , 3 )}$ \\
\hline Medium poor (MP) & $\mathbf{( 1 , 3 , 5 )}$ \\
\hline Fair (F) & $\mathbf{( 3 , 5 , 7 )}$ \\
\hline Medium good (MG) & $\mathbf{( 5 , 7 , 9 )}$ \\
\hline Good & $\mathbf{( 7 , 9 , 1 0 )}$ \\
\hline Very good (VG) & $\mathbf{( 9 , 1 0 , 1 0 )}$ \\
\hline
\end{tabular}

Table 6. Linguistic evaluations of potential failure modes with respect to criteria

\begin{tabular}{|c|c|c|c|c|c|c|c|c|c|}
\hline \multirow{2}{*}{ Failure Modes } & \multicolumn{3}{|c|}{ Severity } & \multicolumn{3}{c|}{ Occurrence } & \multicolumn{3}{c|}{ Detection } \\
\cline { 2 - 11 } & DM1 & DM2 & DM3 & DM1 & DM2 & DM3 & DM1 & DM2 & DM3 \\
\hline Non-conforming material (FM1) & F & F & MP & F & MG & MG & G & MG & G \\
\hline Wrong die (FM2) & P & MP & MP & VG & G & VG & MP & MP & P \\
\hline Wrong program (FM3) & MP & P & MP & VG & G & G & VP & MP & P \\
\hline Excessive cycle time (FM4) & MP & F & MP & F & MG & MG & G & MG & G \\
\hline Wrong process (FM5) & F & F & MP & MG & MG & G & G & VG & G \\
\hline Damaged goods (FM6) & MG & MG & F & MG & G & MG & MP & MP & F \\
\hline Wrong part (FM7) & P & MP & VP & VG & VG & VG & VP & MP & P \\
\hline Incorrect forms (FM8) & VP & VP & P & VP & VP & VP & VP & VP & VP \\
\hline
\end{tabular}

Table 7. Initial aggregated decision matrix

\begin{tabular}{|c|c|c|c|}
\hline Failure Modes & Severity & Occurrence & Detection \\
\hline FM1 & $\mathbf{( 2 . 3 3 3 , 4 . 3 3 3 , 6 . 3 3 3 )}$ & $\mathbf{( 4 . 3 3 3 , 6 . 3 3 3 , 8 . 3 3 3 )}$ & $\mathbf{( 6 . 3 3 3 , 8 . 3 3 3 , 9 . 6 6 7 )}$ \\
\hline FM2 & $\mathbf{( 0 . 6 6 7 , 2 . 3 3 3 , 4 . 3 3 3 )}$ & $\mathbf{( 8 . 3 3 3 , 9 . 6 6 7 , 1 0 )}$ & $\mathbf{( 0 . 6 6 7 , 2 . 3 3 3 , 4 . 3 3 3 )}$ \\
\hline FM3 & $\mathbf{( 0 . 6 6 7 , 2 . 3 3 3 , 4 . 3 3 3 )}$ & $\mathbf{( 7 . 6 6 7 , 9 . 3 3 3 , 1 0 )}$ & $\mathbf{( 0 . 3 3 3 , 1 . 3 3 3 , 3 )}$ \\
\hline FM4 & $\mathbf{( 1 . 6 6 7 , 3 . 6 6 7 , 5 . 6 6 7 )}$ & $\mathbf{( 4 . 3 3 3 , 6 . 3 3 3 , 8 . 3 3 3 )}$ & $\mathbf{( 6 . 3 3 3 , 8 . 3 3 3 , 9 . 6 6 7 )}$ \\
\hline FM5 & $\mathbf{( 2 . 3 3 3 , 4 . 3 3 3 , 6 . 3 3 3 )}$ & $\mathbf{( 5 . 6 6 7 , 7 . 6 6 7 , 9 . 3 3 3 )}$ & $\mathbf{( 7 . 6 6 7 , 9 . 3 3 3 , 1 0 )}$ \\
\hline FM6 & $\mathbf{( 4 . 3 3 3 , 6 . 3 3 3 , 8 . 3 3 3 )}$ & $\mathbf{( 5 . 6 6 7 , 7 . 6 6 7 , 9 . 3 3 3 )}$ & $\mathbf{( 1 . 6 6 7 , 3 . 6 6 7 , 5 . 6 6 7 )}$ \\
\hline FM7 & $\mathbf{( 0 . 3 3 3 , 1 . 3 3 3 , 3 )}$ & $\mathbf{( 9 , 1 0 , 1 0 )}$ & $\mathbf{( 0 . 3 3 3 , 1 . 3 3 3 , 3 )}$ \\
\hline FM8 & $\mathbf{( 0 , 0 . 3 3 3 , 1 . 6 6 7 )}$ & $\mathbf{( 0 , 0 , 1 )}$ & $\mathbf{( 0 , 0 , 1 )}$ \\
\hline
\end{tabular}

By using Eq. (16) we obtain the preferences of the alternatives. As in our example, the number of failure modes are eight in number, hence, $P P_{A} A_{i i}=0.125$. This operation implies that each of the alternatives are given equal preferences. By using Eq. (17), we obtain the matrix of theoretical ponder as shown in Table 8. Each column of Table 8 indicates the theoretical assessment of alternatives for that particular criterion. Usually, in FMAIRCA, initially, decision makers are unbiased towards selecting any particular alternative and hence they are provided with equal preferences. 
Table 8. Fuzzy matrix of theoretical ponder

\begin{tabular}{|l|c|c|c|}
\hline & Severity & Occurrence & Detection \\
\hline FM1 & $(0.037,0.049,0.071)$ & $(0.025,0.033,0.048)$ & $(0.029,0.043,0.052)$ \\
\hline FM2 & $(0.037,0.049,0.071)$ & $(0.025,0.033,0.048)$ & $(0.029,0.043,0.052)$ \\
\hline FM3 & $(0.037,0.049,0.071)$ & $(0.025,0.033,0.048)$ & $(0.029,0.043,0.052)$ \\
\hline FM4 & $(0.037,0.049,0.071)$ & $(0.025,0.033,0.048)$ & $(0.029,0.043,0.052)$ \\
\hline FM5 & $(0.037,0.049,0.071)$ & $(0.025,0.033,0.048)$ & $(0.029,0.043,0.052)$ \\
\hline FM6 & $(0.037,0.049,0.071)$ & $(0.025,0.033,0.048)$ & $(0.029,0.043,0.052)$ \\
\hline FM7 & $(0.037,0.049,0.071)$ & $(0.025,0.033,0.048)$ & $(0.029,0.043,0.052)$ \\
\hline FM8 & $(0.037,0.049,0.071)$ & $(0.025,0.033,0.048)$ & $(0.029,0.043,0.052)$ \\
\hline
\end{tabular}

Next, we obtain the fuzzy normalized decision matrix by using Eq. (18) which is shown in Table

9. This step is necessary to make the aggregated/mean decision matrix dimensionless and comparable.

\begin{tabular}{|c|c|c|c|}
\hline & SeVabig9. Fuzły norogdizadefeeision & matrix Detection \\
\hline FM1 & $(0.122,0.226,0.33)$ & $(0.116,0.169,0.222)$ & $(0.232,0.305,0.354)$ \\
\hline FM2 & $(0.035,0.122,0.226)$ & $(0.222,0.258,0.267)$ & $(0.024,0.085,0.158)$ \\
\hline FM3 & $(0.035,0.122,0.226)$ & $(0.205,0.249,0.267)$ & $(0.012,0.049,0.11)$ \\
\hline FM4 & $(0.087,0.191,0.295)$ & $(0.116,0.169,0.222)$ & $(0.232,0.305,0.354)$ \\
\hline FM5 & $(0.122,0.226,0.33)$ & $(0.151,0.205,0.249)$ & $(0.28,0.341,0.366)$ \\
\hline FM6 & $(0.226,0.33,0.434)$ & $(0.151,0.205,0.249)$ & $(0.061,0.134,0.207)$ \\
\hline FM7 & $(0.017,0.069,0.156)$ & $(0.24,0.267,0.267)$ & $(0.012,0.049,0.11)$ \\
\hline FM8 & $(0,0.017,0.087)$ & $(0,0,0.027)$ & $(0,0,0.037)$ \\
\hline
\end{tabular}

Using Eq. (19), we obtain the matrix of actual ponder as shown in Table 10. This is also known as matrix of real evaluation, which is calculated after considering the criteria weights and making the ratings of alternatives dimensionless.

Table 10. Matrix of fuzzy actual ponder

\begin{tabular}{|c|c|c|c|}
\hline & Severity & Occurrence & Detection \\
\hline FM1 & $(0.004,0.011,0.023)$ & $(0.003,0.006,0.011)$ & $(0.007,0.013,0.019)$ \\
\hline FM2 & $(0.001,0.006,0.016)$ & $(0.006,0.009,0.013)$ & $(0.001,0.004,0.008)$ \\
\hline FM3 & $(0.001,0.006,0.016)$ & $(0.005,0.008,0.013)$ & $(0,0.002,0.006)$ \\
\hline FM4 & $(0.003,0.009,0.021)$ & $(0.003,0.006,0.011)$ & $(0.007,0.013,0.019)$ \\
\hline FM5 & $(0.004,0.011,0.023)$ & $(0.004,0.007,0.012)$ & $(0.008,0.015,0.019)$ \\
\hline FM6 & $(0.008,0.016,0.031)$ & $(0.004,0.007,0.012)$ & $(0.002,0.006,0.011)$ \\
\hline FM7 & $(0.001,0.003,0.011)$ & $(0.006,0.009,0.013)$ & $(0,0.002,0.006)$ \\
\hline FM8 & $(0,0.001,0.006)$ & $(0,0,0.001)$ & $(0,0,0.002)$ \\
\hline
\end{tabular}

By using Eq. (20) and (21) we obtain the final value of criteria functions as shown in Table 11. Decision makers always try to maintain the smallest possible value between theoretical and real evaluation for 
the best alternative and vice-versa. By using our proposed modified approach, we directly calculate the gap values and alternatives are ranked according the ascending order of gap values.

Table 11. Ranking of failure modes by the proposed integrated approach

\begin{tabular}{|c|c|c|c|c|c|c|}
\hline & Severity & Occurrence & Detection & $\begin{array}{c}\text { Value of } \\
\text { criteria } \\
\text { functions }\end{array}$ & $\begin{array}{c}\text { Ranking of } \\
\text { failure } \\
\text { modes }\end{array}$ & $\begin{array}{c}\text { Ranking } \\
\text { obtained } \\
\text { in [34] }\end{array}$ \\
\hline FM1 & 0.040 & 0.030 & 0.029 & 0.0986 & 2 & 2 \\
\hline FM2 & 0.045 & 0.027 & 0.038 & 0.1103 & 5 & 5 \\
\hline FM3 & 0.045 & 0.028 & 0.040 & 0.1121 & 6 & 7 \\
\hline FM4 & 0.041 & 0.030 & 0.029 & 0.1004 & 4 & 4 \\
\hline FM5 & 0.040 & 0.029 & 0.028 & 0.0963 & 1 & 1 \\
\hline FM6 & 0.034 & 0.029 & 0.036 & 0.0986 & 3 & 3 \\
\hline FM7 & 0.048 & 0.027 & 0.040 & 0.1147 & 7 & 6 \\
\hline FM8 & 0.051 & 0.036 & 0.042 & 0.1291 & 8 & 8 \\
\hline
\end{tabular}

We observe that the ranking obtained by our approach is quite similar to the approach presented in [34]. All the failure modes almost have the similar ranking except for FM3 and FM7. The benefits of using this proposed approach and comparison of the result with other MCDM methods are presented in the next section.

\section{Validation and discussion on the obtained ranking result}

In this section we present a threefold validation of the obtained preferences ranking.

Validation 1. We compare out obtained result with other popular MCDM approaches and observe the variations in failure modes ranking. The results are shown in Table 12.

Table 12. Comparison of rankings obtained by different fuzzy MCDM methods

\begin{tabular}{|c|c|c|c|c|c|c|c|}
\hline & $\begin{array}{c}\text { FVIKOR } \\
{[50]}\end{array}$ & $\begin{array}{c}\text { FCOPRAS } \\
{[51]}\end{array}$ & $\begin{array}{c}\text { FMOORA } \\
{[52]}\end{array}$ & $\begin{array}{c}\text { FMABAC } \\
{[53]}\end{array}$ & $\begin{array}{c}\text { FTOPSIS } \\
{[34]}\end{array}$ & $\begin{array}{c}\text { FMAIRCA } \\
{[40]}\end{array}$ & $\begin{array}{c}\text { Proposed } \\
\text { methodology }\end{array}$ \\
\hline FM1 & 2 & 2 & 2 & 2 & 2 & 2 & 2 \\
\hline FM2 & 5 & 5 & 5 & 5 & 5 & 5 & 5 \\
\hline FM3 & 6 & 6 & 6 & 6 & 6 & 6 & 6 \\
\hline FM4 & 3 & 4 & 4 & 4 & 4 & 4 & 4 \\
\hline FM5 & 1 & 1 & 1 & 1 & 1 & 1 & 1 \\
\hline FM6 & 4 & 3 & 3 & 3 & 3 & 3 & 3 \\
\hline FM7 & 7 & 7 & 7 & 7 & 7 & 7 & 7 \\
\hline FM8 & 8 & 8 & 8 & 8 & 8 & 8 & 8 \\
\hline
\end{tabular}

It is observed from Table 12 that by all methods, FM5 is ranked as the most critical failure mode, followed by FM1. By using the FVIKOR approach, we notice that FM4 is ranked as the third critical failure mode and FM6 is ranked as the fourth critical failure mode. Otherwise, all other fuzzy MCDM methods rank FM6 as the third critical failure mode and FM4 as the fourth critical failure mode. However, when we compare the result obtained by Kutlu and Ekmekçioğlu [34] from Table 11, we 
observe that there are rank variations between FM3 and FM7. This is probably due to the application of different criteria weights. In [34] Chang's extent analysis method [39] was adopted, whereas in our approach we used the FAHP method proposed by Buckley [38]. Although we don't observe drastic rank variations between the original work and our proposed approach, it can be claimed that the application of this integrated approach is new in the FMEA domain, is mathematically easier, easy to interpret and requires less computational steps.

Validation 2. In this validation approach we performed a sensitivity analysis and observe the variation in preferences ranking. In real world scenarios, it is often required to change the criteria weights according to the application need. Hence, the method should be sensitive enough to changes in criteria weights. Therefore, in this sensitivity analysis we interchange the criteria weights to get combinations. As there are three criteria in our example, so a total of six combinations can be made. Out of six combinations, weight set -1 was calculated according to the Buckley's [38] FAHP process. In an earlier section, we highlighted that for weight set -1 , the result is consistent $(C R=0.05<0.10)$. As other positive reciprocal matrices are generated by interchanging the linguistic evaluations of Table 3 , so other criteria sets, presented in Table 13 are also consistent and have the same CR. Further, we calculate the spearman's rank correlation coefficient after changing the criteria weights and compare the results with the original work proposed by Kutlu and Ekmekçioğlu [34] and the fuzzy version of the method proposed by Pamucar et al. [40].

Table 13. Set of criteria weights for sensitivity analysis

\begin{tabular}{|c|c|c|c|c|c|}
\hline \multirow{3}{*}{$W_{S O D}$} & \multirow{3}{*}{$\begin{array}{c}\text { Weight set - } \\
1\end{array}$} & Severity & 0.293 & 0.388 & 0.565 \\
\hline & & Occurrence & 0.203 & 0.267 & 0.386 \\
\hline & & Detection & 0.234 & 0.345 & 0.420 \\
\hline \multirow{3}{*}{$W_{S D O}$} & \multirow{3}{*}{$\begin{array}{c}\text { Weight set - } \\
\quad 2\end{array}$} & Severity & 0.293 & 0.388 & 0.565 \\
\hline & & Occurrence & 0.234 & 0.345 & 0.420 \\
\hline & & Detection & 0.203 & 0.267 & 0.386 \\
\hline \multirow{3}{*}{$W_{O D S}$} & \multirow{3}{*}{$\begin{array}{c}\text { Weight set - } \\
3\end{array}$} & Severity & 0.203 & 0.267 & 0.386 \\
\hline & & Occurrence & 0.234 & 0.345 & 0.420 \\
\hline & & Detection & 0.293 & 0.388 & 0.565 \\
\hline \multirow{3}{*}{$W_{O S D}$} & \multirow{3}{*}{$\begin{array}{l}\text { Weight set- } \\
4\end{array}$} & Severity & 0.203 & 0.267 & 0.386 \\
\hline & & Occurrence & 0.293 & 0.388 & 0.565 \\
\hline & & Detection & 0.234 & 0.345 & 0.420 \\
\hline \multirow{3}{*}{$W_{D S O}$} & \multirow{3}{*}{$\begin{array}{l}\text { Weight set - } \\
5\end{array}$} & Severity & 0.234 & 0.345 & 0.420 \\
\hline & & Occurrence & 0.293 & 0.388 & 0.565 \\
\hline & & Detection & 0.203 & 0.267 & 0.386 \\
\hline \multirow{3}{*}{$W_{D O S}$} & \multirow{3}{*}{$\begin{array}{l}\text { Weight set - } \\
6\end{array}$} & Severity & 0.234 & 0.345 & 0.420 \\
\hline & & Occurrence & 0.203 & 0.267 & 0.386 \\
\hline & & Detection & 0.293 & 0.388 & 0.565 \\
\hline
\end{tabular}


The resulting preferences ranking by our proposed approach is shown in Table 14. The average of spearman's rank correlation coefficient is calculated as $96.3 \%$. Further, we observe that the average spearman's rank correlation coefficient obtained by following the fuzzy version of the method proposed in [40] is $96.3 \%$, whereas, the average spearman's rank correlation coefficient of the results presented in [34] was $94.2 \%$. Now at this point, we can highlight the following two things:

- Rank correlation between our method and the fuzzy version of the method proposed in [40] is the same. Although, the superiorities of our method are firstly, it incorporates a normalization technique which helps in hard computation and increases calculation accuracy. When the number of criteria increases, it becomes quite difficult for the decision maker to identify the benefit and cost criteria. However, in this normalization technique there is no requirement of that identification. Secondly, we reduce the step of de-fuzzification after obtaining the total gap matrix. To do that, we simply calculate the fuzzy Euclidian distance between elements of the matrix of theoretical and actual ponder, which no doubt is more realistic than the simple subtraction operation.

- We can observe from Table 14 that when we vary the criteria weight, there are variations in preferences ranking. Hence, our method is sensitive to criteria weights. FM5 is consistently ranked as the most critical failure mode. There are changes in rank between FM1, FM4 and FM6. However, we do not observe any changes in ranking for FM2, FM3, FM7 and FM8. In fact, stability of the ranking results are better than the method proposed in [34]. Hence, we say that the ranking result obtained by our proposed approach is confirmed, credible and robust.

Table 14. Variations in preferences ranking by varying the criteria weights

\begin{tabular}{|c|c|c|c|c|c|c|}
\hline & $W_{S O D}$ & $W_{S D O}$ & $W_{O D S}$ & $W_{O S D}$ & $W_{D S O}$ & $W_{D O S}$ \\
\hline FM1 & 2 & 3 & 2 & 2 & 3 & 2 \\
\hline FM2 & 5 & 5 & 5 & 5 & 5 & 5 \\
\hline FM3 & 6 & 6 & 6 & 6 & 6 & 6 \\
\hline FM4 & 4 & 4 & 3 & 3 & 4 & 3 \\
\hline FM5 & 1 & 1 & 1 & 1 & 1 & 1 \\
\hline FM6 & 3 & 2 & 4 & 4 & 2 & 4 \\
\hline FM7 & 7 & 7 & 7 & 7 & 7 & 7 \\
\hline FM8 & 8 & 8 & 8 & 8 & 8 & 8 \\
\hline
\end{tabular}

Validation 3. In MCDM theory, it is considered as a major problem to validate the obtained preferences ranking as no standard methods are currently available. In some works [43], the authors devised a few techniques for validation, however, it is noticed that most of them are case-specific. Most of them validate the ranking result by comparison with other standard methods or by changing the criteria weights as presented earlier. Here, we propose an indirect technique for validation of the ranking result. Let us assume that we want to verify the ranking result between two alternatives $\left(A_{1}, A_{2}\right)$ which are already ranked by any MCDM approach, and $A_{1}$ is superior than $A_{2}$. 
Let the decision matrix be expressed as shown in Eq. (22):

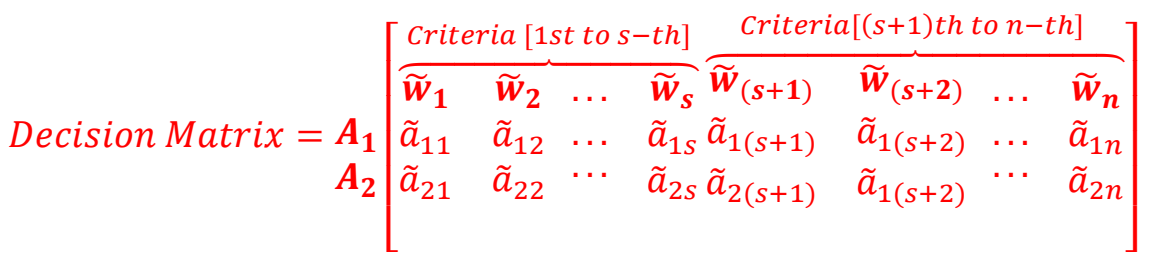

Using Eq. (7) or (8), we defuzzify each of the elements of the decision matrix as represented in Eq. (23):

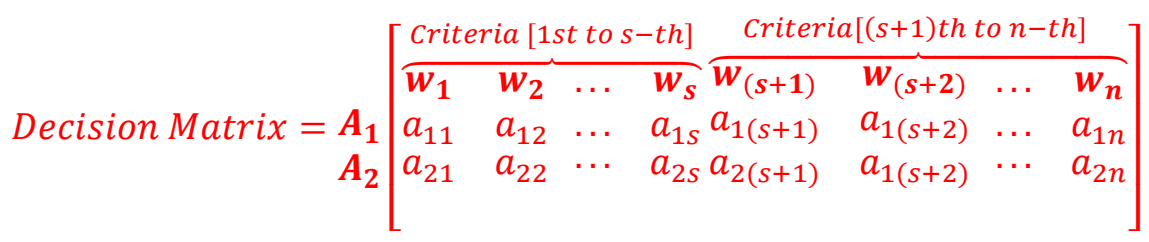

Then for each evaluation we compare their values. For simplicity in understanding, suppose that for $s$ number of criteria $(s \leq n), a_{i j}>a_{(i+1) j}$ and for $(s+1) t h-n$, the number of criteria $a_{i j}<a_{(i+1) j}$. We discard those cases where $a_{i j}=a_{(i+1) j}$. Now for $A_{1}$ to be a better choice than $A_{2}$, it is required that $\sum_{i=1}^{s} w_{i}>\sum_{i=(s+1)}^{n} w_{i}$.

Below, in Table 15, we present two examples in support of our proposed validation method. We now consider the solved example of the FMEA problem presented in Section 4.

Table 15. Examples in support of Validation-3

\section{Example - 1: Comparison between FM1 and FM5}

- From Table 7 and using Eq. (7) we obtain the following decision matrix:

$$
\text { Decision Matrix }=F M_{1}\left(\begin{array}{ccc}
w_{S}=0.395 & w_{O}=0.272 & w_{D}=0.333 \\
4.333 & 6.333 & 8.222 \\
4.333 & 7.611 & 9.167
\end{array}\right)
$$

- Now, for 'severity', defuzzified ratings are the same for both of the failure modes and hence we discard it. For the other two risk factors, ratings of FM5 are superior to FM1. Hence, their respective weights are considered and summed up. The output becomes $w_{O}+w_{D}=$ $0.272+0.333=0.605$.

- As none of the evaluation for FM1 is superior to FM5, so there is no necessity for further calculation. Thus, FM5 is more critical rather than FM1. 
- In this example, we examine the credibility of ranking results between FM3 and FM7. This is because the ranking result obtained by our approach is slightly different than the result presented in [34].

- From Table 7 and using Eq. (7) we obtain the following decision matrix:

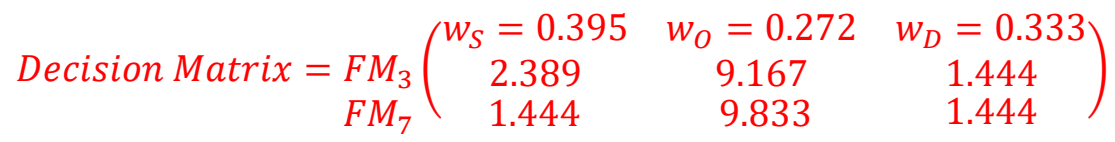

- Now, for 'detection', defuzzified ratings are the same for both of the failure modes and hence we discard it. For, 'severity', the rating of FM3 is superior to FM7. Whereas, for 'occurrence', the ratings of FM7 are superior to FM3.

- Next, we check the value of criteria weights. FM3 is ranked as more critical than FM7, as $u w_{S}>w_{O}$.

Now using the approach given above, it is easily inferred that FM3 is more critical than FM7, whereas the ranking result presented in [34] violates the above principle and thus we can say that our ranking result is better than their approach. This is probably due to the fact that FMAIRCA produces more stable results than FTOPSIS.

\section{Managerial implications and conclusion}

In this work a novel integrated MCDM approach is proposed by combining FAHP and FMARICA for solving a complex decision-making task related to FMEA. To validate the potentiality of our approach we have considered a benchmark example of FMEA which was previously solved by the FAHP and FTOPSIS approach. In the original work, FAHP, based on the extent analysis method was used to derive the relative importance between the risk factors. However, that has received several criticisms till now and most importantly, sometimes it provides zero criteria value for some application cases, which is not possible at all. We have used the same pairwise comparison matrix as given in the original work and have utilized Buckley's FAHP approach (geometric mean approach) to calculate the relative importance among the risk factors. In the next task, to rank the failure modes, we have proposed a modified FMAIRCA approach, where we have replaced the normalization formulae and used the Euclidian distance to calculate the gap between actual and theoretical ponder. We believe that our approach is computationally faster, more accurate and requires less computational steps than the original steps involved in the MAIRCA method. We have compared our ranking result with the original work of the FAHP-FTOPSIS approach and found out that the ranking stability of our approach is higher. Apart from that, when the number of risk factors and alternatives are increased, our approach is sufficient to handle that situation and still provides credible ranking results. Next, we have proposed a new approach to validate the obtained ranking result by using the MCDM approach, which is quite simpler to interpret 
and is derived from simpler human reasoning. This integrated approach is believed to be a feasible choice among the risk analysts in industries to support the complex risk assessment task of FMEA.

Further development of this approach is suggested to incorporate other distance measures and to compare the deviation from the mean performance score. Apart from that, other weight calculation approaches may be combined with FMAIRCA to improve the decision-making process.

\section{Acknowledgements}

The authors would like to show gratitude to the Ministry of Human Resources and Development (MHRD), India and Curtin University, Western Australia for providing financial assistances to carry out this work. They would also like to thank Indian Institute of Technology Kharagpur, India and Curtin University, Western Australia for making a collaborative program for carrying out the research work.

\section{References}

[1] Gargama H, Chaturvedi SK. Criticality assessment models for failure mode effects and criticality analysis using fuzzy logic. IEEE Transactions on Reliability 2011;60:102-110.

[2] Standard M. Procedures for performing a failure mode, effects and criticality analysis. Department of Defense, Washington, DC, Standard No MIL-STD-1629A 1980.

[3] Song W, Ming X, Wu Z, Zhu B. Failure modes and effects analysis using integrated weight-based fuzzy TOPSIS. International Journal of Computer Integrated Manufacturing 2013;26:1172-1186.

[4] Bian T, Zheng H, Yin L, Deng Y. Failure mode and effects analysis based on D numbers and TOPSIS. Quality and Reliability Engineering International 2018;34:501-515.

[5] Wang Z, Gao J-M, Wang R-X, Chen K, Gao Z-Y, Zheng W. Failure mode and effects analysis by using the house of reliability-based rough VIKOR approach. IEEE Transactions on Reliability 2018;67:230-248.

[6] Tian Z, Wang J, Zhang H. An integrated approach for failure mode and effects analysis based on fuzzy best-worst, relative entropy, and VIKOR methods. Applied Soft Computing 2018;72:636646.

[7] Mariajayaprakash A, Senthilvelan T. Failure detection and optimization of sugar mill boiler using FMEA and Taguchi method. Engineering Failure Analysis 2013;30:17-26.

[8] Chang K-H, Chang Y-C, Tsai I-T. Enhancing FMEA assessment by integrating grey relational analysis and the decision making trial and evaluation laboratory approach. Engineering Failure Analysis 2013;31:211-224.

[9] Liu H-C, Li Z, Song W, Su Q. Failure mode and effect analysis using cloud model theory and PROMETHEE method. IEEE Transactions on Reliability 2017;66:1058-1072.

[10] Commission IE, others. IEC 60812: Analysis techniques for system reliability-Procedure for failure mode and effects analysis (FMEA). Geneva, Switzerland: International Electrotechnical Commission 2006:1-93. 
[11] Liu H-C, Wang L-E, Li Z, Hu Y-P. Improving Risk Evaluation in FMEA With Cloud Model and Hierarchical TOPSIS Method. IEEE Transactions on Fuzzy Systems 2019;27:84-95.

[12] Certa A, Enea M, Galante GM, La Fata CM. ELECTRE TRI-based approach to the failure modes classification on the basis of risk parameters: An alternative to the risk priority number. Computers \& Industrial Engineering 2017;108:100-110.

[13] Xiao N, Huang H-Z, Li Y, He L, Jin T. Multiple failure modes analysis and weighted risk priority number evaluation in FMEA. Engineering Failure Analysis 2011;18:1162-1170.

[14] Panchal D, Singh AK, Chatterjee P, Zavadskas EK, Keshavarz-Ghorabaee M. A new fuzzy methodology-based structured framework for RAM and risk analysis. Applied Soft Computing 2019;74:242-254.

[15] Huang J, Li ZS, Liu H-C. New approach for failure mode and effect analysis using linguistic distribution assessments and TODIM method. Reliability Engineering \& System Safety 2017;167:302-309.

[16] Lo H-W, Liou JJ, Huang C-N, Chuang Y-C. A novel failure mode and effect analysis model for machine tool risk analysis. Reliability Engineering \& System Safety 2019;183:173-183.

[17] Zadeh LA. Fuzzy sets. Information and Control 1965;8:338-353.

[18] Liu H-C, Liu L, Liu N. Risk evaluation approaches in failure mode and effects analysis: A literature review. Expert Systems with Applications 2013;40:828-838.

[19] Liu H-C, Chen X-Q, Duan C-Y, Wang Y-M. Failure mode and effect analysis using multi-criteria decision making methods: A systematic literature review. Computers \& Industrial Engineering 2019.

[20] Asan U, Soyer A. Failure mode and effects analysis under uncertainty: a literature review and tutorial. Intelligent Decision Making in Quality Management, Springer; 2016, p. 265-325.

[21] Du Y, Mo H, Deng X, Sadiq R, Deng Y. A new method in failure mode and effects analysis based on evidential reasoning. International Journal of System Assurance Engineering and Management 2014;5:1-10.

[22] Chang K-H. A novel general risk assessment method using the soft TOPSIS approach. Journal of Industrial and Production Engineering 2015;32:408-421.

[23] Carpitella S, Certa A, Izquierdo J, La Fata CM. A combined multi-criteria approach to support FMECA analyses: A real-world case. Reliability Engineering \& System Safety 2018;169:394402.

[24] Das Adhikary D, Kumar Bose G, Bose D, Mitra S. Multi criteria FMECA for coal-fired thermal power plants using COPRAS-G. International Journal of Quality \& Reliability Management 2014;31:601-614.

[25] Wang L-E, Liu H-C, Quan M-Y. Evaluating the risk of failure modes with a hybrid MCDM model under interval-valued intuitionistic fuzzy environments. Computers \& Industrial Engineering 2016;102:175-185. 
[26] Liu H-C, You J-X, Chen S, Chen Y-Z. An integrated failure mode and effect analysis approach for accurate risk assessment under uncertainty. Iie Transactions 2016;48:1027-1042.

[27] Liu H-C, Fan X-J, Li P, Chen Y-Z. Evaluating the risk of failure modes with extended MULTIMOORA method under fuzzy environment. Engineering Applications of Artificial Intelligence 2014;34:168-177.

[28] Zhao H, You J-X, Liu H-C. Failure mode and effect analysis using MULTIMOORA method with continuous weighted entropy under interval-valued intuitionistic fuzzy environment. Soft Computing 2017;21:5355-5367.

[29] Fattahi R, Khalilzadeh M. Risk evaluation using a novel hybrid method based on FMEA, extended MULTIMOORA, and AHP methods under fuzzy environment. Safety Science 2018;102:290300.

[30] Liu H-C, You J-X, Duan C-Y. An integrated approach for failure mode and effect analysis under interval-valued intuitionistic fuzzy environment. International Journal of Production Economics 2019;207:163-172.

[31] Gugaliya A, Boral S, Naikan V. A hybrid decision making framework for modified failure mode effects and criticality analysis: A case study on process plant induction motors. International Journal of Quality \& Reliability Management 2019.

[32] Satty TL. The analytic hierarchy process. New York: McGraw-Hill; 1980.

[33] Emrouznejad A, Marra M. The state of the art development of AHP (1979-2017): a literature review with a social network analysis. International Journal of Production Research 2017;55:6653-6675.

[34] Kutlu AC, Ekmekçioğlu M. Fuzzy failure modes and effects analysis by using fuzzy TOPSISbased fuzzy AHP. Expert Systems with Applications 2012;39:61-67.

[35] Panchal D, Chatterjee P, Shukla RK, Choudhury T, Tamosaitiene J. INTEGRATED FUZZY AHP-CODAS FRAMEWORK FOR MAINTENANCE DECISION IN UREA FERTILIZER INDUSTRY. Economic Computation \& Economic Cybernetics Studies \& Research 2017;51.

[36] Chatterjee P, Stević Ž. A two-phase fuzzy AHP-fuzzy TOPSIS model for supplier evaluation in manufacturing environment. Operational Research in Engineering Sciences: Theory and Applications 2019;2:72-90.

[37] Van Laarhoven PJ, Pedrycz W. A fuzzy extension of Saaty's priority theory. Fuzzy Sets and Systems 1983;11:229-241.

[38] Buckley JJ. Fuzzy hierarchical analysis. Fuzzy Sets and Systems 1985;17:233-247.

[39] Chang D-Y. Applications of the extent analysis method on fuzzy AHP. European Journal of Operational Research 1996;95:649-655.

[40] Pamučar D, Vasin L, Lukovac L. Selection of railway level crossings for investing in security

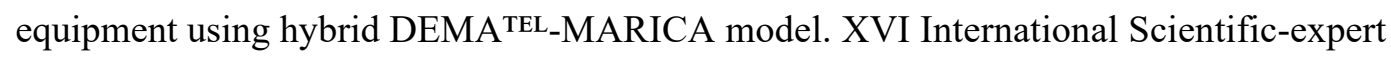
Conference on Railway, Railcon, 2014, p. 89-92. 
[41] Gigović L, Pamučar D, Bajić Z, Milićević M. The combination of expert judgment and GISMAIRCA analysis for the selection of sites for ammunition depots. Sustainability 2016;8:372.

[42] Pamučar D, Mihajlović M, Obradović R, Atanasković P. Novel approach to group multi-criteria decision making based on interval rough numbers: Hybrid DEAMEL-ANP-MAIRCA model. Expert Systems with Applications 2017;88:58-80.

[43] Chatterjee K, Pamucar D, Zavadskas EK. Evaluating the performance of suppliers based on using the R'AMA' ${ }^{\mathrm{TEL}}$-MAIRCA method for green supply chain implementation in electronics industry. Journal of Cleaner Production 2018;184:101-129.

[44] Pamucar DS, Tarle SP, Parezanovic T. New hybrid multifiteria decision-making DEMATEL_ MAIRCA model: sustainable selection of a location for the development of multimodal logistics centre. Economic Research-Ekonomska Istraživanja 2018;31:1641-1665.

[45] Pamučar DS, Ćirović G, Božanić D. APPLICATION OF INTERVAL VALUED FUZZYROUGH NUMBERS IN MULTI-CRITERIA DECISION MAKING: THE IVFRN-MAIRCA MODEL. Yugoslav Journal of Operations Research 2019.

[46] Wang Y-M, Luo Y, Hua Z. On the extent analysis method for fuzzy AHP and its applications. European Journal of Operational Research 2008;186:735-747.

[47] Ribeiro RA. Fuzzy multiple attribute decision making: a review and new preference elicitation techniques. Fuzzy Sets and Systems 1996;78:155-181.

[48] Krohling RA, de Souza TT. Combining prospect theory and fuzzy numbers to multi-criteria decision making. Expert Systems with Applications 2012;39:11487-11493.

[49] Hasheminasab H, Hashemkhani Zolfani S, Bitarafan M, Chatterjee P, Ezabadi AA. The Role of Façade Materials in Blast-Resistant Buildings: An Evaluation Based on Fuzzy Delphi and Fuzzy EDAS. Algorithms 2019;12:119.

[50] Opricovic S. Fuzzy VIKOR with an application to water resources planning. Expert Systems with Applications 2011;38:12983-12990.

[51] Zarbakhshnia N, Soleimani H, Ghaderi H. Sustainable third-party reverse logistics provider evaluation and selection using fuzzy SWARA and developed fuzzy COPRAS in the presence of risk criteria. Applied Soft Computing 2018;65:307-319.

[52] Akkaya G, Turanoğlu B, Öztaş S. An integrated fuzzy AHP and fuzzy MOORA approach to the problem of industrial engineering sector choosing. Expert Systems with Applications 2015;42:9565-9573.

[53] Bozanic D, Tešić D, Milićević J. A hybrid fuzzy AHP-M ABAC model: Application in the Serbian Army-The selection of the location for deep wading as a technique of crossing the river by tanks. Decision Making: Applications in Management and Engineering 2018;1:143-164. 